\title{
Examining the Socio-economic Determinants of Broadband Adopters and Non-adopters in the United Kingdom
}

\author{
Jyoti Choudrie \\ DISC, SISCM, Brunel University, UK \\ Jyoti.Choudrie@btopenworld.com
}

\author{
Yogesh K. Dwivedi \\ DISC, SISCM, Brunel University, UK \\ ykdwivedi@gmail.com
}

\begin{abstract}
The aim of this study was to examine the socioeconomic determinants of broadband adopters and non-adopters in the United Kingdom (UK). The study was conducted using a postal survey. A selfadministered questionnaire was sent to 1600 households and a total of 358 replies were obtained from the respondents. This study confirms the findings obtained from a previous study that examined the socio-demographic attributes of the household consumers of broadband technologies in local vicinity, the London Borough of Hillingdon. The findings of this survey support the view the socioeconomic attributes such as age, gender, education, income and occupation have an imperative role in explaining the adoption of broadband in the household. A brief discussion on the implications and contributions is also provided in the conclusion of the paper.
\end{abstract}

\section{Introduction}

Broadband is considered to be an innovation for the technology area as it offers better access and quality of the Internet $[6,18]$. The deployment and exploitation of broadband is expected to offer several benefits. These are considered to be: (i) the delivery of economic value and an increase in GDP growth; (ii) to deliver public value by improving education and health; (iii) to improve people's lives from all segments of society; and finally, (iv) delivering efficiencies in the public sector via e-Government provision $[6,18]$. It has been argued that there is a direct link between investment on information and communication technologies (ICTs) development and the government's ability to deliver efficient savings in the public services [6]. Therefore, in order to achieve efficiency targets and to improve service delivery to citizens, government departments are developing and promoting the use of transactional e-government services [6]. Broadband is considered vital for the growth and diffusion of emerging e-government services $[6,11]$. This is because broadband users are more likely to be aware of new e-Government services [11] and a higher tendency to transact online for product and services [6]. As discussed above since broadband has the potential to affect the national economy in a number of ways, the issues regarding the adoption and usage of it, which in turn affects the management of it, have become a matter of priority in the current global environment including the UK.

Studies on the adoption and usage of the internet suggest that socio-economic attributes such as income, educational attainment and the current employment status of household consumers have a positive correlation with internet access rates. However, the age of a household consumer has a negative correlation with Internet access rates $[1,2]$. Early findings from previous studies represent the socio-economic characteristics of innovators, which may or may not represent the early and late adopters [21]. A recent study specifically examined the role of socio-demographic attributes such as the age, gender, education, income and social status of UK residential broadband consumers $[9,12]$. However, the findings of this study were limited since the data was collected from a small vicinity within the UK, the London Borough of Hillingdon. Subsequently, this led to a larger study that encompassed the nation in order to confirm and generalize the previous findings [9, 12]. Utilizing the aforementioned reasoning as a motivating factor the aim of this study was to examine the socio-economic determinants of broadband adopters and non-adopters in the UK. An additional aim was to determine the similarities and variations between the previous and current studies.

The beneficiaries of this research are several including, initially the government. The gradual adoption of broadband has been an issue of contentment and one that the UK government has been particularly sensitive to and is undertaking substantial steps such as, making the deployment of 
broadband an aim that should be fulfilled [4]. Due to the residential consumers' slow adoption of broadband industry has become concerned about the wider adoption and diffusion of it. By obtaining results such as those afforded by this research and the previous study, the reasons for slow adoption can be explored and appropriate measures to overcome them can be developed and implemented. Therefore this research is expected to offer a contribution to all the interested stakeholders including the Internet Service Providers (ISPs) and government agencies who may want to identify the adopters and non-adopters and develop future strategies that will obtain an increasing number of sustainable subscribers

The paper begins with a brief discussion of research undertaken on the adoption of broadband in section 2. Thereafter, a theoretical basis is provided in section 3. Section 4 provides a brief discussion of the utilized research method. The findings are presented and discussed in Section 5. Finally, a conclusion to the research is provided in section 6 .

\section{Background}

A focus of this research is that of the consumers of broadband, and at this point the differentiating factor between the terms of consumers and users is provided. According to Rice [20] 'consumers' are those who pay for services and goods, while, 'users' are individuals who are affected by or who affect the product or services. For example, a child as a 'user' employs broadband to play online games and to undertake homework, but he/she cannot subscribe to it; however, parents who pay for the subscription are termed as 'consumers'.

When examining the literature surrounding the deployment of broadband it was found that the research on the demand perspective is limiting. Henceforth, the discussed adoption studies mainly provide discussions of the macro factors that drive the success or slow uptake of broadband deployment. In an initial study of broadband deployment in South Korea, Lee et al. [17] identified three major factors that explained the high rate of broadband adoption in South Korea. Further research suggested that six success factors are responsible for driving the high penetration rate of broadband within the South Korean residential consumers [16]. To obtain a UK perspective Dwivedi et al. [14] examined the ISPs views on the factors affecting broadband adoption in the UK. The exploratory study suggested that a high price, lack of content, and lack of awareness are the factors that are severely affecting the adoption of broadband amongst the residential consumers. Other exploratory studies that examined the factors affecting the deployment of broadband in the various countries across the globe include Sweden [22], Australia and Canada [8].

From the analysis of previous studies it was found that the focus of the aforementioned research on the adoption of broadband internet access has been mainly concentrated at the macro-level [18]. Factors such as government strategy and encouragement, market competition, and experiences of successful nations with minimal attention paid to exploring the characteristic of adopters from the non-adopters was undertaken. In a recent study Stanton [23] emphasized the need to conduct an inquiry that addresses the access question and the demographics that would be useful to observe any changes in the likelihood of socioeconomic groups when adopting broadband [23]. Following that, Choudrie and Dwivedi $[9,12]$ examined the socio-economic attributes of broadband consumers in a local vicinity, the London Borough of Hillingdon. However the limitation of this study [9, 12] was that the data was collected from a small sample, so the findings could not be generalized to the whole UK population. Bearing that in mind it was suggested that a national level survey should be conducted to confirm the findings. Therefore, this research progressed a further step in order to confirm the consumer demographic characteristics of the adopters and non-adopters of broadband in the UK. Given the slow uptake of broadband adoption in many countries including the UK, it was felt that such research would be beneficial since it would identify the particular segments of society that need to be encouraged and motivated to adopt broadband internet in the home.

\section{Theoretical basis}

Households are considered to be a form of social organization [27]. Therefore, any study that examines household associated issues should also include all those variables that have been suggested as key variables when undertaking social investigations [7]. Key variables such as age, education, gender, income and occupation [7] provide important information on the characteristics of the population under investigation. This theoretical claim is supported by findings from the regression analysis of the USA census data [25]. The results indicate that the most important variables when considering the adoption factors are, gender, race, education, and income. Previous studies that examined the adoption of ICTs such as the computer [25, 27], the telephone [3], internet [2] and broadband [1] in the households and its subsequent impact on users have included these variables. Since home computers, the telephone, and 
the internet are grouped within the same technology cluster [21], the socioeconomic variables that have been employed to study one technology can also be used to study the others. Therefore, variables such as age, education, occupation, and income that were utilized to examine home computers adoption in the households can also be employed to study broadband adoption. Since a detailed discussion on the selection and appropriateness of the aforementioned socioeconomic variables was provided in a previous study $[9,12]$, further justification upon these issues is not offered.

\section{Research methodology}

As information on large numbers of the population was essential for this research, empirical research via a survey research method was considered to be an appropriate approach [10]. Nationwide data on the adoption of broadband was collected from various households in the UK.

\subsection{Sample frame}

This research utilised UK-Info Disk V11 CD-ROM as a sample frame. UK-Info Disk V11 is directly derived from the electoral register, which is considered as the most comprehensive and reliable sample frame for the UK population [20]. UK-Info Disk V11 is updated regularly and includes 31 million electoral roll records [19]. Therefore, it is considered to be a fair representative of the UK population.

The structure of the sample frame [19] necessitated the adoption of a stratified random sampling approach to collect unbiased data from the target population. Within the UK-Info Disk V11 database, the entire UK population was listed in alphabetical order and according to the surname or family name. The first step was to extract a respondent address from each letter of the alphabet. Then the sample size for each alphabet was determined according to the total sample size. Thereafter a unique random number for each alphabetical letter was generated using research randomizer software. Respondents to the corresponding random numbers were then selected for data collection from the sample frame.

\subsection{Survey instrument}

In order to collect random data for the target population, a self-administered questionnaire was considered to be the most appropriate primary survey instrument in this investigation. A self administered questionnaire was utilised because: it addressed the issue of reliability of information by reducing and eliminating differences in the way by which the questions are asked [13]; there are relatively low costs of administration and can be accomplished with minimal facilities; it provides access to widely dispersed samples; respondents have time to give thoughtful answers; help asking questions with long or complex response categories; asking similar repeated questions; and also the respondents does not have to share answers with interviewers [15].

Overall, the questionnaire used in this research contained a total of 8 questions (See Appendix). These questions were divided into two broad categories: (1) multiple choice questions addressing the social attributes (demographic variables) including age, gender, education, occupation and income; and (2) Yes/No questions to determine whether the respondents possessed the technology in question, which is broadband. Close-ended multiple-choice questions were included in the questionnaire in order to obtain a high response rate. This is due to instances where respondents preferred to answer close-ended question within non-interactive, self-administered questionnaires [15].

\subsection{Instrument validation and questionnaire administration}

Prior to dissemination of the final questionnaire, a pilot study was conducted to: determine the response rate and learn of any discrepancies within the questions, which included determining whether the format of the questionnaire and questions were suitable. Additionally, the duration involved in completing the questionnaire was also established. The pilot questionnaire was delivered via the post to a total of randomly selected 200 participants from UKInfo Disk V11 database in December 2004. A total of 40 replies were obtained from the respondents within the specified duration. The majority of the respondents reported that the questionnaire was easily understood and required 10 to 15 minutes for completion. The majority of the respondents validated the content of the questionnaires, although minor changes to the final design of the questionnaire were undertaken based upon the received feedback and a final questionnaire was developed. Since there were no major changes required to incorporate in questionnaire, responses received from the pilot study were also included in the final analysis [15].

\subsection{Sample size and questionnaire administration}

Fowler [15] has suggested that the prerequisite for determining sample size should be an analysis plan. 
This paper is a part of a larger study on broadband diffusion in the UK household. Analysis of the entire study required performing principal component analysis (PCA), regression analysis, $t$-test and chisquare tests. It has been suggested that in order to achieve rigor to the aforementioned statistical analysis, the sample size should be above 300 [24]. Therefore, keeping the statistical analysis plan in mind it was decided that the total sample size should be large enough to obtain a minimum of 300 responses. Therefore the total sample size was determined by using the pilot response rate as a basis of the final survey. Total sample size $=[$ Total responses required*100] / Pilot response rate]

Total sample size $=300 * 100 / 20=\mathbf{1 5 0 0}$

As illustrated above a total of 1500 sample size was required to achieve 300 responses. To compensate for any shortfalls in the 300 responses that may occur due to the undelivered and partially completed responses, the sample size was increased further from 1500 to 1600 . Therefore, a total sample size of 1600 was considered appropriate for this study. The final questionnaires were sent using the postal service. A covering letter and a self-addressed prepaid return envelope were administered to a total of 1600 household consumers in the UK in the periods between Jan 2005 and March 2005.

\subsection{Response rate}

Of the overall 1600 sent questionnaires, 300 questionnaires replies were received within the specified periods. From these, 280 questionnaires were usable and 20 were either undeliverable or incomplete questionnaires. This implied that a response rate of 17.5 percent was obtained. To test the response bias, 200 questionnaires were sent to randomly selected non-respondents from the original sample in mid March 2005. 40 questionnaire replies were received and comprised 38 usable and 2 partially completed questionnaires. The reasoning for the aforementioned was that suggested by Fowler [15]. Fowler [15] suggests that 'if the new round of data collection replicates questions in the initial survey, the results can be added to the initial sample data set'. Table 1 illustrates that there were no significant differences in terms of age, gender, education, internet access and type of internet access between the original respondents and a sample of non-respondents. Therefore, following the suggestion from Fowler [15], the responses received from the pilot study and from the non-respondents were added to the original responses. After combining the original response of 280 with the 38 responses from the non-response bias and the 40 responses from the pilot study, a final response rate was estimated [15]. The obtained final response rate was 17.9 percent.

\subsection{Data analysis}

The collated data was analyzed using SPSS version 11.5. This allowed the calculation of the response frequencies, percentages and chi-square values to analyze the variables determined by this research. The aforementioned statistics were used due to previous information systems (IS) researchers employing the earlier stated analysis tools to analyze and present research findings using response frequencies and percentages $[26,28]$ and after experiencing it the researchers felt it was most suitable for this research's purposes. Since the variables included within this paper were nominal in nature, the chi-square $\left(\chi^{2}\right)$ test was therefore considered to be the most appropriate method [5] to test the statistical significance for examining the non-response bias.

\subsection{Non-response bias test}

To determine whether the characteristics of the original responses' respondents are similar to those of the non-respondents, a chi-square $\left(\chi^{2}\right)$ test was conducted for the following demographic variables: age, gender and education [15], internet access at home, and type of internet connection at home. The findings are illustrated in Table 1.

\section{Table 1. Non-response bias test}

\begin{tabular}{|l|l|l|l|}
\hline Variables & $\boldsymbol{\chi}^{\mathbf{2}}$ Value & df & Sig. \\
\hline Age X Response Type (RT) & 6.90 & 5 & .22 \\
\hline Gender X RT & .312 & 1 & .57 \\
\hline Education X RT & 5.43 & 4 & .24 \\
\hline Internet Access X RT & .419 & 1 & .51 \\
\hline Type of Connection X RT & 2.58 & 1 & .10 \\
\hline
\end{tabular}

The chi-square value is not significant for all six variables (Table 1). This suggests that those nonrespondents who returned the completed questionnaire after reminders were similar to the respondents from the original responses.

\section{Findings}

\subsection{Respondents profile}

The survey respondents' profiles revealed that of the 358 received responses, $26.1 \%$ of the respondents belonged to the 25-34 years age group, which formed the largest response category. The 35-44 years age group with $21.6 \%$ follows this. The least responsive category was the 65 years and above with $3.9 \%$. In 
terms of gender only $2 \%$ more responses were obtained from the male respondents (51\%) in comparison to the females $(49 \%)$ (Table 2). The majority of the respondents possessed educational qualifications-a degree (34.6\%) and postgraduate level education (29.3\%). The least responsive educational category was GNVQ/Diploma with an $8.8 \%$ response rate. $11.7 \%$ of the respondents possessed GCSE level (i.e. high school) education followed by ' $A$ ' level with a $15.5 \%$ response rate (Table 2).

Table 2. Profile of survey participants

\begin{tabular}{|l|l|l|l|l|}
\hline $\begin{array}{c}\text { Variable } \\
\text { Category }\end{array}$ & Percent & & \multicolumn{1}{|c|}{$\begin{array}{c}\text { Variable } \\
\text { Category }\end{array}$} & Percent \\
\hline \multicolumn{2}{|c|}{ Age (N=357) } & & \multicolumn{2}{c|}{ Occupation (N=345) } \\
\hline$<=24$ & 21.0 & & $\mathrm{~A}$ & 10.6 \\
\hline $25-34$ & 26.1 & & $\mathrm{~B}$ & 27.4 \\
\hline $35-44$ & 21.6 & & $\mathrm{C} 1$ & 19.0 \\
\hline $45-54$ & 19.0 & & $\mathrm{C} 2$ & 2.0 \\
\hline $55-64$ & 8.4 & & $\mathrm{D}$ & 1.7 \\
\hline$>=65$ & 3.9 & & $\mathrm{E}$ & 35.8 \\
\hline \multicolumn{2}{|c|}{ Gender $\mathbf{( N = 3 5 5 )}$} & & Annual Income (N=347) \\
\hline Male & 50.6 & & $<=10 \mathrm{~K}$ & 9.2 \\
\hline Female & 48.6 & & $10-19 \mathrm{~K}$ & 16.8 \\
\hline \multicolumn{2}{|c|}{ Education (N=341) } & & $20-29 \mathrm{~K}$ & 17.3 \\
\hline GCSC & 11.2 & & $30-39 \mathrm{~K}$ & 16.8 \\
\hline GNQV & 8.4 & & $40-49 \mathrm{~K}$ & 10.6 \\
\hline A Level & 14.8 & & $50-59 \mathrm{~K}$ & 7.0 \\
\hline Degree & 33.0 & & $60-69 \mathrm{~K}$ & 9.2 \\
\hline PG & 27.9 & & $=>70 \mathrm{~K}$ & 10.1 \\
\hline
\end{tabular}

The occupational category with the highest amount of respondents was ' $E$ ' that consisted of students, casual workers, and pensioners (37.1\%); followed by category ' $\mathrm{B}$ ' which consisted of managers, teachers, and computer programmers (28.4\%). C1 represented the third largest occupational category with $19.7 \%$ responses followed by category ' $\mathrm{A}$ ' with $11.0 \%$ responses. The least responsive occupational categories were ' $\mathrm{D}$ ' and ' $\mathrm{C} 2$ ' with a response rate of $1.7 \%$ and $2.0 \%$ respectively (Table 2 ). Responses for the household income categories varied between $17.9 \%$ for the $£ 20-29 \mathrm{~K}$ and $7.2 \%$ for $£ 50-59 \mathrm{~K}$ category. The least annual household income group $(<=£ 10 \mathrm{~K})$ was represented by a $9.5 \%$ response, whilst the largest income group $(=>£ 70 \mathrm{~K})$ was represented with a $10.4 \%$ response rate (Table 2 ).

\subsection{Internet adoption rate}

Table 3 illustrates that of the 358 respondents, 308 $(86 \%)$ had internet access at home and $50(14 \%)$ did not. Of the 308 respondents who possessed internet at home, $101(28.2 \%)$ had a narrowband connection and the remainder $207 \quad(57.8 \%)$ had a broadband connection (Table 3).
Table 3. Adoption of Internet in London borough of Hillingdon and in the UK

\begin{tabular}{|l|c|c|}
\hline & \multicolumn{2}{|c|}{ Percentage Adoption } \\
\hline Internet Type & Hillingdon (N=172) & UK (N=358) \\
\hline Dial-up & $39 \%$ & $28.2 \%$ \\
\hline Broadband & $29.7 \%$ & $57.8 \%$ \\
\hline Total Adopters & $\mathbf{6 8 . 7 \%}$ & $\mathbf{8 6 \%}$ \\
\hline
\end{tabular}

\subsection{Internet access at alternative places}

This survey also examined alternative locations that respondents accessed the Internet from. A previous study $[9,12]$ that examined broadband adoption in the London borough of Hillingdon had not included this variable. Table 4 illustrates that 61.2 percent of the respondents also had access to the internet at work followed by 36 percent of the respondents had access within the University and college.

\section{Table 4. Internet access at alternative places}

\begin{tabular}{|l|c|c|}
\hline & \multicolumn{2}{|l|}{ Percentage Respondents } \\
\hline \multicolumn{1}{|c|}{ Alternative Place } & Yes & No \\
\hline Work Place & 61.2 & 38.8 \\
\hline University or College & 36.0 & 64.0 \\
\hline Public Access Point & 5.6 & 94.4 \\
\hline Local Library & 17.9 & 82.1 \\
\hline Internet café & 13.4 & 86.6 \\
\hline Others & 1.4 & 98.6 \\
\hline
\end{tabular}

An alternative form of access was also provided by the local library (17.9 percent). This was followed by the internet café where access to the internet was obtained by 13.4 percent of the respondents. Only 5.6 percent of the respondents utilised public access points to access the Internet. The others category that consisted of a 1.4 percent response rate included respondents who accessed the Internet from friends and relatives homes and with the mobile phone whilst on the move (Table 4).

\subsection{Respondent age and broadband adoption}

Table 5 illustrates the adoption of broadband by consumers within the UK, which is interestingly increasing with age; however the subscription rate falls after 44 years and no subscribers were reported at the $>75$ years category. The majority of broadband subscribers fell between the 25-54 years. The findings illustrated in Table 5 suggest that broadband consumers hail from the young and middle-aged groups; however the older age group consists of mainly non-adopters. This is because this age group consists of mostly non-computer users who may not possess the skill and knowledge to use a computer and the internet. A comparison of the findings from a 
previous study in Hillingdon and this national level survey both illustrate similar patterns with very small variations (Table 5). This suggests that the variableage-has an imperative role in the diffusion of broadband in the UK. Early predictions of the impact of consumer age and broadband adoption were confirmed in this study. It was expected that the older aged people are less likely to subscribe to broadband, which was supported by the findings of this research.

Table 5. Percentage of adopters and nonadopters according to age group

\begin{tabular}{|c|l|l|l|c|}
\hline & \multicolumn{2}{|c|}{ Adopters } & \multicolumn{2}{c|}{ Non-Adopters } \\
\hline Age & Hillingdon & UK & Hillingdon & UK \\
\hline $17-24$ & 11.8 & 24.2 & 14.1 & 16.7 \\
\hline $25-34$ & 23.5 & 24.2 & 16.7 & 28.7 \\
\hline $35-44$ & 17.6 & 23.7 & 20.5 & 18.7 \\
\hline $45-54$ & 25.5 & 18.8 & 21.8 & 19.3 \\
\hline $55-64$ & 11.8 & 8.2 & 17.9 & 8.7 \\
\hline $65-74$ & 9.8 & 1.0 & 7.7 & 5.3 \\
\hline$>75$ & 0 & 0.0 & 1.3 & 2.7 \\
\hline
\end{tabular}

\subsection{Respondent gender and broadband adoption}

In terms of gender differences, Table 6 illustrates that there are more male broadband consumers (53.6 percent) than females (46.4 percent). This pattern is similar to a previous study. However, very minor difference occurred between the findings of the two studies, specifically when comparing non-adopters (Table 6). In a previous study the non-adopters consisted of more females (51.3 percent) than the males (48.7 percent). Similarly, this study also suggests the same pattern. That is, there are more female non-adopters (52.7 percent) than male (47.3 percent). Therefore, the findings from both the studies suggest very narrow variations when considering the adoption rates of the two genders (Table 6).

Table 6. Percentage of adopters and nonadopters according to Gender

\begin{tabular}{|c|c|c|c|c|}
\hline & \multicolumn{2}{|c|}{ Adopters } & \multicolumn{2}{c|}{ Non-Adopters } \\
\hline Gender & Hillingdon & UK & Hillingdon & UK \\
\hline Male & 58.5 & 53.6 & 48.7 & 47.3 \\
\hline Female & 41.2 & 46.4 & 51.3 & 52.7 \\
\hline
\end{tabular}

\subsection{Respondent education and broadband adoption}

Table 7 illustrates the educational attainment of broadband adopters and non-adopters. The findings of a previous study [9] suggested that the majority of adopters are educated to the GCSE level followed by respondents who had attained degree level education.
Respondents with 'A' level and postgraduate degrees also illustrated a similar percentage, which is 15.7 percent (Table 7).

Table 7. Percentage of adopters and nonadopters according to Education

\begin{tabular}{|l|l|l|l|l|}
\hline & \multicolumn{2}{|c|}{ Adopters } & \multicolumn{2}{c|}{ Non-Adopters } \\
\hline \multicolumn{1}{|c|}{ Education } & Hillingdon & UK & Hillingdon & UK \\
\hline GCSE & 27.5 & 5.0 & 19.2 & 21.3 \\
\hline GNVQ/Diploma & 3.9 & 7.5 & 5.1 & 10.6 \\
\hline A level & 15.7 & 15.5 & 14.1 & 15.6 \\
\hline Degree & 23.5 & 39.0 & 25.6 & 28.4 \\
\hline PG & 15.7 & 33.0 & 17.9 & 24.1 \\
\hline
\end{tabular}

The findings of a previous study did not demonstrate any clear relationship between the role of education and broadband adoption in Hillingdon. Contrastingly, this survey clearly explained the impact of education upon the adoption of broadband by consumers'. The findings illustrated in Table 7 suggest that the higher the level of education the more likely those consumers will subscribe to broadband. This suggests that adoption rates increase with the level of educational attainment. The majority of the adopters are educated to the degree level (39 percent) followed by respondents who had postgraduate level education (33 percent). The least percentage of adopters ( 5 percent) possessed GCSE level education. Therefore, this survey confirmed the role of education upon the diffusion of new technologies, in this instance, broadband internet (Table 7).

\subsection{Respondent income and broadband adoption}

The findings from both the previous and current studies suggest that as the annual household income of consumers increases, so does the adoption rate. Table 8 illustrates that in both the studies adopters with the least percentage attained an annual household income of less than $£ 10 \mathrm{~K}$. What was learnt from this research was that adopters with the highest percentage (16.8 percent) belong to the category of an annual household income of $£ 20-29 \mathrm{~K}$. This is contrary to the previous study where the annual household incomes of the highest numbers of adopters hailed from the $£ 10-19 \mathrm{~K}, £ 30-39 \mathrm{~K}$ and $=>70 \mathrm{~K}$ categories. The findings of the previous study did not determine a clear relationship between income and the adoption of broadband; however, this research confirmed this by revealing that the majority of adopters possessed high household annual incomes (Table 8). 
Table 8. Percentage of adopters and nonadopters according to annual

\begin{tabular}{|l|l|l|l|l|}
\hline & \multicolumn{2}{|c|}{ Adopters } & \multicolumn{2}{c|}{ Non-Adopters } \\
\hline Income & Hillingdon & \multicolumn{1}{|c|}{ UK } & Hillingdon & UK \\
\hline$<10 \mathrm{~K}$ & 3.9 & 9.4 & 6.4 & 9.7 \\
\hline $10-19 \mathrm{~K}$ & 15.7 & 10.4 & 10.3 & 26.9 \\
\hline $20-29 \mathrm{~K}$ & 11.8 & 16.8 & 16.7 & 19.3 \\
\hline $30-39 \mathrm{~K}$ & 15.7 & 15.3 & 15.4 & 20.0 \\
\hline $40-49 \mathrm{~K}$ & 9.8 & 13.9 & 11.5 & 6.9 \\
\hline $50-59 \mathrm{~K}$ & 13.7 & 9.9 & 11.5 & 3.4 \\
\hline $60-69 \mathrm{~K}$ & 5.9 & 10.9 & 11.5 & 7.6 \\
\hline$=>70 \mathrm{~K}$ & 15.7 & 13.4 & 10.3 & 6.2 \\
\hline
\end{tabular}

\subsection{Occupation of broadband adoption}

The occupation list categories were derived from the marketing literature where mainstream professionals such as, doctors, lawyers, and judges with the responsibility of more then 25 staff are classified as occupational category 'A' [20]. The aforementioned occupations with a responsibility of less then 25 staff and academics are grouped as social grade 'B'. Skilled-non-manual workers fall within the occupational category ' $\mathrm{C} 1$ ' and ' $\mathrm{C} 2$ '. Unskilled manual workers belong to the occupational category 'D'. Finally, social grade ' $E$ ' consists of pensioners, casual workers, unemployed and students [20].

Table 9 describes the occupational category for both the adopters and non-adopters. The findings of previous studies suggest that none of the adopters and non-adopters of broadband are from occupational category 'A'. However, the results of this research found that respondents from occupational category ' $A$ ' are mainly adopters rather then non-adopters. Similarly occupational category 'B' consisted of an increasing number of adopters (33.7 percent) rather then non-adopters $(21$ percent). The largest percentage of both adopters (36.6 percent) and nonadopters (37.8 percent) belonged to occupational category 'E' (Table 9). This research also learnt that respondents from higher occupational categories are more likely to subscribe to broadband and adoption rates increase as the occupational category improves. Therefore both the current and previous studies confirmed and established the role of the variable 'occupation' when understanding the adoption and diffusion of broadband in the UK. The reason for this can be attributed to occupation being a better predictor for broadband adoption and non-adoption. Income and education considered comparatively less effective predictors as consumers belonging to the higher occupational category possess both higher education and income; hence, a positive attitude towards adoption. Contrastingly, if consumers belonged to a lower occupational category then they are more likely to have both lower educational attainment and lower income; thereby a less positive attitude towards technology adoption [9, 12].

\section{Table 9. Percentage of adopters and non- adopters from different occupational category}

\begin{tabular}{|l|l|l|l|l|}
\hline \multirow{2}{*}{$\begin{array}{c}\text { Occupational } \\
\text { category }\end{array}$} & \multicolumn{2}{|c|}{ Adopters } & \multicolumn{2}{c|}{ Non-Adopters } \\
\cline { 2 - 5 } & Hillingdon & UK & Hillingdon & UK \\
\hline $\mathrm{A}$ & 0 & 12.9 & 0 & 8.4 \\
\hline $\mathrm{B}$ & 3.9 & 33.7 & 3.8 & 21.0 \\
\hline $\mathrm{C} 1$ & 56.9 & 14.9 & 52.6 & 26.6 \\
\hline $\mathrm{C} 2$ & 9.8 & 1.5 & 9 & 2.8 \\
\hline $\mathrm{D}$ & 11.8 & 0.5 & 7.7 & 3.5 \\
\hline $\mathrm{E}$ & 17.6 & 36.6 & 26.9 & 37.8 \\
\hline
\end{tabular}

\section{Conclusions}

This research examined the socio-economic determinants of broadband adopters and non-adopters of broadband in the UK households. It also confirms the findings obtained from an initial and exploratory study that was conducted in a local community, the London borough of Hillingdon. This study supports the previous findings that suggest that when considering the adoption of broadband, the findings of other similar home technologies such as computers can be used. This implies that the demographic characteristics of consumers such as age, gender and social grade are pertinent when explaining the adoption of broadband in the household. However, unlike the findings of the previous study $[9,12]$ this research also found that demographic characteristics such as income and education level are as important as age, gender and social grade when distinguishing the adopters from non-adopters. This is evident from the findings that broadband subscribers are those who have achieved both higher education levels as well as higher annual household incomes.

The following two important policy issues arise from this research. First, the issue of the digital divide, which refers to the inequitable diffusion of broadband in UK society $[9,29,30]$, particularly since the findings of this study suggest disparity in terms of age, gender, education, income and occupation between the adopters and non-adopters. This highlights the need for affordability and accessibility of emerging ICTs and applications such as e-Government services for all segments of society. In order to promote the equitable diffusion of ICTs such as broadband, it is essential that high-speed internet access provision to citizens with lower education, income and occupation level and also to elderly people should be provided in the form of public access points. Such public access points should 
either be free of charge or a minimal fee should be imposed. Further, technical support should be offered. Public access points will help excluded citizens to become aware of new services and benefits and at the same time gain confidence when using ICTs.

Second, the issue of digital choice which refers to an individual or citizen's choice when considering the adoption or rejection of ICTs such as, broadband [29, 30]. The finding suggests that there are non-adopters of broadband who possess high annual household income, higher education level and higher occupation. This is also an obstacle when considering the homogenous diffusion of broadband in the UK. Therefore, both ISPs and policy makers have to find a means of persuading non-adopters from affluent groups of the UK society to adopt broadband and other emerging ICTs such as, e-government services.

Both the aforementioned problems indicated by all initial studies focused upon broadband and eGovernment adoption and diffusion $[9,11,12,29$, 30]. Therefore, without eliminating the problems of the digital divide and digital choice it may not be possible to realize the real benefits that new ICTs offer in terms of cost reduction, increase in efficiency, GDP growth and improving citizens lives [6].

\subsection{Limitations}

This national survey overcomes the limitation of the previous study $[9,12]$ where the sample was drawn from a small vicinity within London. This prevented the findings of that study from being generalized to the entire UK population. In this survey the sample was drawn from the overall UK population; therefore generalizations can be made. However, the limitation of this national survey was that the response rate was low; therefore, the confidence level in findings was limited. However, conducting a non-response bias test led to surmounting of this limitation [15] and illustrates reliability and confidence in the findings of this national survey.

\subsection{Future research directions}

Since this was a self-administered survey, by keeping the response rate in mind [15] only closed ended questions were included. It restricted the researcher's ability to ask open-ended questions [15], which might have assisted in offering a better understanding of why particular segments of society are adopting or rejecting subscribing to broadband. To overcome this limitation, future studies may employ data collection methods such as, interviews or focus groups that will examine the adoption and diffusion of new ICTs such as, broadband and e-Government services.

This study further emphasizes the suggestions made by previous studies $[9,23]$. That is, in order to highlight cross-cultural differences it will also be interesting to compare the demographic characteristics of UK broadband consumers to other leading broadband countries such as, the United States of America, Canada and Australia. Due to the unavailability of such studies [23], it is not possible to make such a comparison within this research; however, it is recommended that future research should investigate such issues.

This research has offered contributions by demonstrating that older aged people at both the local and national levels are slow in adopting broadband. Slow adoption may occur due to the following three important reasons: (i) not sufficient resources i.e. incomes are not sufficient enough to subscribe to broadband; (ii) the majority of older aged people do not have the necessary skills to operate the computer and Internet; (iii) they do not know of the potentials that broadband offers. Future research should focus on confirming if the aforementioned reasons or other reasons are responsible for the slow adoption of broadband. If future research confirms the aforementioned reasons, the key challenge for policy makers will then be to implement approaches that involve the older aged citizens of the mainstream information society. Recently the UK government has made available online a number of services that are especially beneficial for older aged people, including the pension and council tax services. However, if the older citizens are reluctant to use the Internet then the diffusion of these e-Government services will be very sluggish. Hence, it is important to pay attention to such age groups.

This research also suggests that consumers younger than 24 years are slow in adoption. In future research it will be important to understand the reasons for the majority of consumers below 24 years being slow in adoption. This may be because the majority of respondents below 24 years are either studying or just beginning employment and may not be able to afford the current price plan. If future research confirms that then the ISPs may need to consider alternative price plans in order to create a mass-market demand.

This research also indicates that consumers with a high annual household income are also reluctant to subscribe to broadband. Future research needs to understand reasons (for example, the lack of compelling-ness or lack of needs) for the low adoption in higher income segments. If possible reasons are found to be lack of compelling-ness, then the challenge to the ISPs will be to integrate content and applications and make the consumers aware of them. 


\section{References}

[1] Anderson, B., Gale, C., Jones, M. and McWilliam, A., "Domesticating broadband-what consumers really do with flat-rate, always-on and fast internet access", $B T$ Technology Journal, 2002, 20 (1), 103-114.

[2] Anderson, B. and Tracey, K., "Digital Living: The Impact (or Otherwise) of the Internet on Everyday Life", American Behavioral Scientist, 2001, 45 (3), 456-475.

[3] Anderson, B., McWilliam, A., Lacohee, H., Clucas, E. and Gershuny, J., "Family Life in Digital Home- Domestic Telecommunications at the end of the $20^{\text {th }}$ century", $B T$ Technology Journal, 1999, 17, (1), 85-97.

[4] Arnott, S., "Broadband Can't Wait for Government", Computing, May 2002. Viewed on: http://www.computing.co.uk/Analysis/1131983

[5] Brace, N., Kemp, R. and Snelgar, R., SPSS for Psychologists: A Guide to Data Analysis Using SPSS for Windows, Palgrave Macmillan, New York, 2003.

[6] BSG Briefing Paper. "The Impact of Broadband-enabled ICT, Content, Applications and Services on the UK Economy and Society to 2010. London, United Kingdom, 2004. Available From: http://www.broadbanduk.org/news/news pdfs/Sept $\% 20200$ 4/BSG Phase 2 BB Impact BackgroundPaper Sept04(1). pdf, Accessed 30 October 2004.

[7] Burgess, R., Key Variables in Social Investigation, Routledge, London, 1986.

[8] Chang, S., Lee, H. and Middleton, C., "The deployment of broadband Internet in Australia: Areas for Attention and Implications from Canada and Korea". Proceedings of the ITS Asia- Australasian Regional Conference on MBusiness, E-Commerce and the Impact of Broadband on Regional Development and Business Prospects, Perth, Australia, 2003.

[9] Choudrie, J. and Dwivedi, Y.K., "The demographics of broadband residential consumers of a British local community: The London Borough of Hillingdon", Journal of Computer Information Systems, 2005, 45 (4), 93-101.

[10] Choudrie, J. and Dwivedi, Y.K., "Investigating the Research Approaches for examining the Technology Adoption in the Household", Journal of Research Practice, 2005, 1 (1)

[11] Choudrie, J. and Dwivedi, Y. "A Survey of Citizens' Awareness and Adoption of e- Government Initiatives, the 'Government Gateway': A United Kingdom Perspective", Proceedings of the E-Gov. 2005 workshop,

DISC, Brunel University, London, UK.

[12] Choudrie, J. and Dwivedi, Y., "Investigating the Socio-economic Characteristics of Residential Consumers of Broadband in the UK", Proceedings of AMCIS 2004, New York, USA, August 6-8, 1558-1567, 2004.
[13] Cornford, T. and Smithson, S., Project Research in Information Systems: A Student's Guide, Macmillan Press Ltd, London, 1996.

[14] Dwivedi, Y.K., Choudrie, J. and Utam, G.S. "Broadband stakeholders analysis: ISPs perspective", Proceedings of the ITS Asia- Australasian Regional Conference on M-Business, E-Commerce and the Impact of Broadband on Regional Development and Business Prospects, Perth, Australia, 2003.

[15] Fowler, F.J., Survey Research Methods, SAGE Publications Inc., London, 2002.

[16] Lee, H. and Choudrie, J., "Investigating Broadband Technology Deployment in South Korea", Report of Brunel- DTI International Technology Services Mission to South Korea, DISC, Brunel University, Uxbridge, UK, 2002.

[17] Lee, H., O'Keefe, B. and Yun, K., "The growth of broadband and electronic commerce in South Korea: contributing factors", The Information Society, 2003, 19, 81-93.

[18] Oh, S., Ahn J. and Kim B., "Adoption of broadband Internet in Korea: the role of experience in building attitude", Journal of Information Technology, 18, 267-280, 2003

[19] People Finder (UK-Info Disk V11) at http://www.192.com/products/productdetails.cfm?item id= 46.

[20] Rice, C., Understanding Customers, ButterworthHeinemann, Oxford, 1997.

[21] Rogers, E.M., Diffusion of Innovations, Free Press, New York, 1995.

[22] Shim, Y., Lee, H. and Yun, K., "The Growth of Broadband Internet in Sweden: Contributing factors",

Proceedings of the ITS Asia- Australasian Regional Conference on M-Business, E-Commerce and the Impact of Broadband on Regional Development and Business Prospects, Perth, Australia, 2003.

[23] Stanton, L.J. "Factors influencing the adoption of residential broadband connections to Internet", Proceedings of the $37^{\text {th }}$ Hawaii International Conference on System Sciences, Hawaii, 2004.

[24] Stevens, J., Applied Multivariate Statistics for the Social Sciences, Lawrence Erlbaum Associates, New Jersey, 1996.

[25] Venkatesh, A., Chuan-Fong, Shih, E. and Norman, C., "A longitudinal analysis of computing in the home census data 1984-1997", In Home informatics and Telematics: Information, Technology and Society. Sloane and Felix van Rijn (Eds) pp 205-215, 2000.

[26] Venkatesh, V. and Brown, S., "A longitudinal investigation of personal computers in homes: adoption determinants and emerging challenges", MIS Quarterly, 2001, 25 (1), 71-102. 
[27] Vitalari, N. P., Venkatesh, A., and Gronhaug, K., "Computing in the Home: Shifts in the Time Allocation Patterns of Household", Communications of the ACM, 1985, $28(5), 512-522$.

[28] Webster, J., "Desktop Videoconferencing: Experiences of complete users, wary users, and non-users", MIS Quarterly, 1998, 22 (3), 257-286.

[29] William, D., Gennaro, di, C., and Hargrave, A.M., "The Internet in Britain: The Oxford Internet survey", May 2005. Available
http://www.oii.ox.ac.uk/research/oxis/OxIS 2005 Internet Survey.pdf

[30] William, D., and Gennaro, di, C., "Digital inclusion: the 2005 Oxford Internet survey", 2005. Available at http://www.oii.ox.ac.uk/research/oxis/oxis2005_results.pdf

\title{
Appendix: Questionnaire for Broadband Diffusion Survey
}

\author{
Internet cafe
}

Other (Please specify)...

[1] What age (Years) group do you belong to?

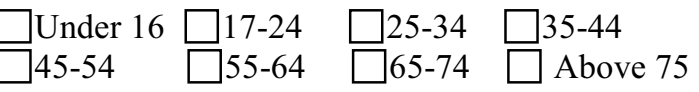

[2] Gender

Male

Female

\section{[3] Highest level of education}

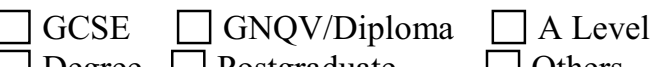

$\square$ Degree $\square$ Postgraduate $\square$ Others

\section{[4] What is your occupation?}

Directors, doctors, lawyers, professors

$\square$ Managers, teachers, computer programmers

$\square$ Foremen, shop assistants, office workers

$\square$ Electricians, mechanics, plumbers

$\square$ Machine operators, assembly, cleaning

$\square$ Pensioners, casual workers, unemployed, students

$\square$ Others (Please specify)...

[5] What is your household's annual income? (K= £1000)

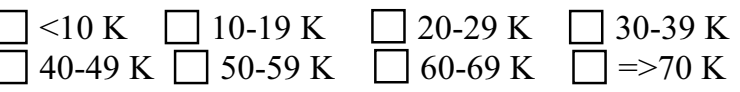

[6] Do you have Internet access at home?

$\square$ Yes $\square$ No

[7] If you do have Internet access, what would you describe the type of Internet is that you do have?

Dial-up $\square$ Broadband

[8] Where else do you obtain access to the Internet? (Please tick all applicable options)

$\square$ Work place

Local library
University or college

Public access points 